\title{
BMJ Global Health A landscape analysis of universal health coverage for mothers and children in South Asia
}

Katy Scammell, ${ }^{1}$ Douglas J Noble, ${ }^{1}$ Kumanan Rasanathan, ${ }^{2}$ Thomas O'Connell, ${ }^{2}$ Aishath Shahula Ahmed, ${ }^{3}$ Genevieve Begkoyian, ${ }^{4}$ Tania Goldner, ${ }^{5}$ Renuka Jayatissa, ${ }^{6}$ Lianne Kuppens, ${ }^{7}$ Hendrikus Raaijmakers, ${ }^{8}$ Isabel Vashti Simbeye, ${ }^{9}$ Sherin Varkey, ${ }^{10}$ Mickey Chopra ${ }^{2}$

To cite: Scammell K, Noble DJ, Rasanathan K, et al. A landscape analysis of universal health coverage for mothers and children in South Asia. BMJ Global Health 2016;1:e000017. doi:10.1136/bmjgh-2015000017

Received 25 November 2015 Revised 16 March 2016 Accepted 19 April 2016

\section{CrossMark}

${ }^{1}$ UNICEF Regional Office for South Asia, Kathmandu, Nepal

${ }^{2}$ UNICEF Headquarters, New York, New York, USA ${ }^{3}$ UNICEF Maldives, Male, Maldives

${ }^{4}$ UNICEF India, New Delhi, India

${ }^{5}$ UNICEF Pakistan, Islamabad,

Pakistan

${ }^{6}$ UNICEF Sri Lanka, Colombo, Sri Lanka

${ }^{7}$ UNICEF Bangladesh, Dhaka Bangladesh

${ }^{8}$ UNICEF Nepal, Kathmandu, Nepal

${ }^{9}$ UNICEF Bhutan, Thimpu,

Bhutan

${ }^{10}$ UNICEF Afghanistan, Kabul, Afghanistan

Correspondence to Dr Douglas J Noble; djnoble@unicef.org

\section{ABSTRACT}

The United Nations made universal health coverage (UHC) a key health goal in 2012 and it is one of the Sustainable Development Goals' targets. This analysis focuses on UHC for mothers and children in the 8 countries of South Asia. A high level overview of coverage of selected maternal, newborn and child health services, equity, quality of care and financial risk protection is presented. Common barriers countries face in achieving UHC are discussed and solutions explored. In countries of South Asia, except Bhutan and Maldives, between $42 \%$ and $67 \%$ of spending on health comes from out-of-pocket expenditure (OOPE) and government expenditure does not align with political aspirations. Even where reported coverage of services is good, quality of care is often low and the poorest fare worst. There are strong examples of ongoing successes in countries such as Bhutan, the Maldives and Sri Lanka. Related to this success are factors such as lower 00PE and higher spending on health. To make progress in achieving UHC, financial and non-financial barriers to accessing and receiving high-quality healthcare need to be reduced, the amount of investment in essential health services needs to be increased and allocation of resources must disproportionately benefit the poorest.

\section{UNIVERSAL HEALTH COVERAGE IN SOUTH ASIA}

In 2005, Member States of the WHO adopted a World Health Assembly resolution stating that all citizens should have access to health services without suffering financial hardship. ${ }^{1}$ Subsequently, in 2012, the United Nations General Assembly adopted a resolution on global health and foreign policy that called for action towards universal health coverage (UHC). ${ }^{2}$ The World Bank and the WHO have selected UHC as a key objective to address both the right to health and extreme poverty. ${ }^{3}$ In 2015, achieving UHC became a target for the Sustainable Development Goals under goal three (target

\section{Key questions}

What is already known about this topic?

- The United Nations made universal health coverage a key health goal in 2012 and it is one of the Sustainable Development Goals' targets.

- To achieve UHC, countries need to ensure that their population has access to quality health services at a cost that people can afford.

What are the new findings?

- In South Asia, political aspirations for Universal Health Coverage are not yet well reflected in spending and health outcomes for women and children.

- Although there are political aspirations, and schemes and plans that attempt to address the poorest, there is not enough progress for the neediest populations.

- There are a few examples of success that can in part be related to lower out-of-pocket expenditure and higher spending on health overall.

\section{Recommendations for policy}

- Governments and development partners need to prioritise coverage of essential health interventions, quality of care, equity and financial risk protection.

- Civil society and development partners can assist with formulating and costing plans and strategies, identifying critical service gaps, promoting evidence-based practice and improving quality of data collection.

- While general principles for achieving UHC can be applied across different countries, context specific solutions are needed that take into account the complexity of different health systems.

3.8- Achieve universal health coverage, including financial risk protection, access to quality essential healthcare services and access to safe, effective, quality and affordable essential medicines and vaccines for 
all'). ${ }^{4}$ In order to achieve this, countries need to ensure their population has access to high-quality health services at a cost people can afford. The use of these services should not expose any user to financial hardship and should be equitable. ${ }^{5}$

Achieving the vision of UHC globally will have significant benefits for maternal, newborn and child health (MNCH). Yet, despite previous progress on millennium development goals four and five for MNCH across South Asia, ${ }^{6}$ millions of mothers and children still do not receive the health services they need at a cost they can afford.

Measuring progress on UHC is complex due to the political context in countries and the absence of reliable data. The World Bank and the WHO have suggested measures that can be used to monitor UHC. Health service coverage can be assessed based on essential promotion, prevention, treatment, rehabilitation and palliation services. Financial risk protection can be estimated by considering both impoverishing expenditure (degree to which health expenditure moves families below the poverty line) and catastrophic expenditure (health payments that are higher than a household's resources). And, equity can be judged by using measures disaggregated by socioeconomic and demographic strata. ${ }^{7}$

Countries need to select a suite of measures that are most relevant, based on their context. Metrics need to be collected in a standardised and routine way, to improve comparability across time as well as between countries. ${ }^{8}$

This landscape analysis focuses on UHC for mothers and children in the eight countries of South Asia, using the domains that the WHO and the World Bank advise monitoring (coverage with good quality essential services and financial protection), ${ }^{7}$ and triangulating with selected quantitative and qualitative $\mathrm{MNCH}$ data from South Asia. Common barriers countries face in achieving UHC are discussed, and ways forward for governments and partners suggested.

\section{EQUITABLE COVERAGE OF MATERNAL, NEWBORN AND CHILD HEALTH SERVICES}

Increasing coverage of $\mathrm{MNCH}$ services is a core part of progress towards UHC. In South Asia as a whole, the proportion of pregnant women who receive four antenatal visits is low in most countries (figure 1). Less than a third of women receive four antenatal care visits in Afghanistan and Bangladesh. ${ }^{9}$ At the time of birth, reported coverage of skilled birth attendants is also low (figure 2). About half or more women in Afghanistan, Bangladesh, India and Pakistan give birth without the support of a skilled birth attendant. ${ }^{10}$

Exclusive breastfeeding in under 6-month-olds is variable and indicates different levels of support available to women postbirth as well as social norms (table 1). Afghanistan has the highest coverage rates in the region
(83\%), with India (46\%) and Pakistan (38\%) having the lowest rates. ${ }^{11}$

Immunisation coverage measured by surviving infants who receive a third dose of diphtheria, tetanus and pertussis (DTP3)-containing vaccine (an overall marker of health system performance), reveals several poorperforming countries, despite recent improvements. In Afghanistan, India and Pakistan, 17-27\% of infants still do not receive DTP3. ${ }^{12}$

The proportion of children under 5 years with diarrhoea who are treated with oral rehydration salts/an appropriate household solution (ORT) is low in some South Asian countries. In India, only $26 \%$ of children with diarrhoea received ORT, according to the latest available international data, although there may have been improvements in more recent years. Coverage remains poor in Pakistan, with $41.8 \%$ of children receiving ORT. ${ }^{13}$

Many children with suspected acute respiratory infections (ARI) do not receive appropriate treatment. Coverage is very low in Nepal $(7 \%)$, with the highest coverage rate seen in Bangladesh $(71.4 \%){ }^{13}$

Equity in reported coverage of services is also a major issue. With the exception of the Maldives, in all countries where data are available, there are marked differences in antenatal care coverage between different wealth quintiles (figure 3). In Nepal, $88 \%$ of women in the highest quintile received antenatal care at least four times, compared to $30 \%$ in the lowest quintile. In Pakistan, women in the highest quintile are six times more likely to receive at least four antenatal care visits than those in the lowest quintile. ${ }^{14}$

Skilled birth attendance follows a similar pattern: in Bangladesh, India, Nepal and Pakistan, 73.4\%, 84.9\%, $93.3 \%$ and $85.2 \%$ of the richest wealth quintile received skilled birth attendance, compared to $17.9 \%, 23.6 \%$, $25.5 \%$ and $29.8 \%$ in the poorest wealth quintile, respectively. ${ }^{15}$

Availability of prevention services for children also demonstrates stark inequities. For example, with the exception of the Maldives, in countries where data are available, there are considerable differences between DTP3 vaccination coverage between different wealth quintiles (figure 4).

Across the region, there is lower reported coverage of services in rural areas. In Pakistan, wide provincial and urban/rural disparities exist in maternal, neonatal and child mortality rates. ${ }^{17}$ In India, there is a larger number of services in urban areas, despite the fact that over two-thirds of the population live in rural areas. ${ }^{18-20} \mathrm{In}$ Bangladesh, there is an inequitable distribution of health professionals biased towards urban areas, ${ }^{21-23}$ leading to stark inequities such as $55 \%$ of women in urban areas having skilled birth attendance, compared to just $28 \%$ in rural areas. ${ }^{24}$ However, the urban poorest in Bangladesh can fare even worse than those living in rural areas: for example, as few as $15 \%$ of those living in slums have had skilled birth attendance. ${ }^{25}$ 


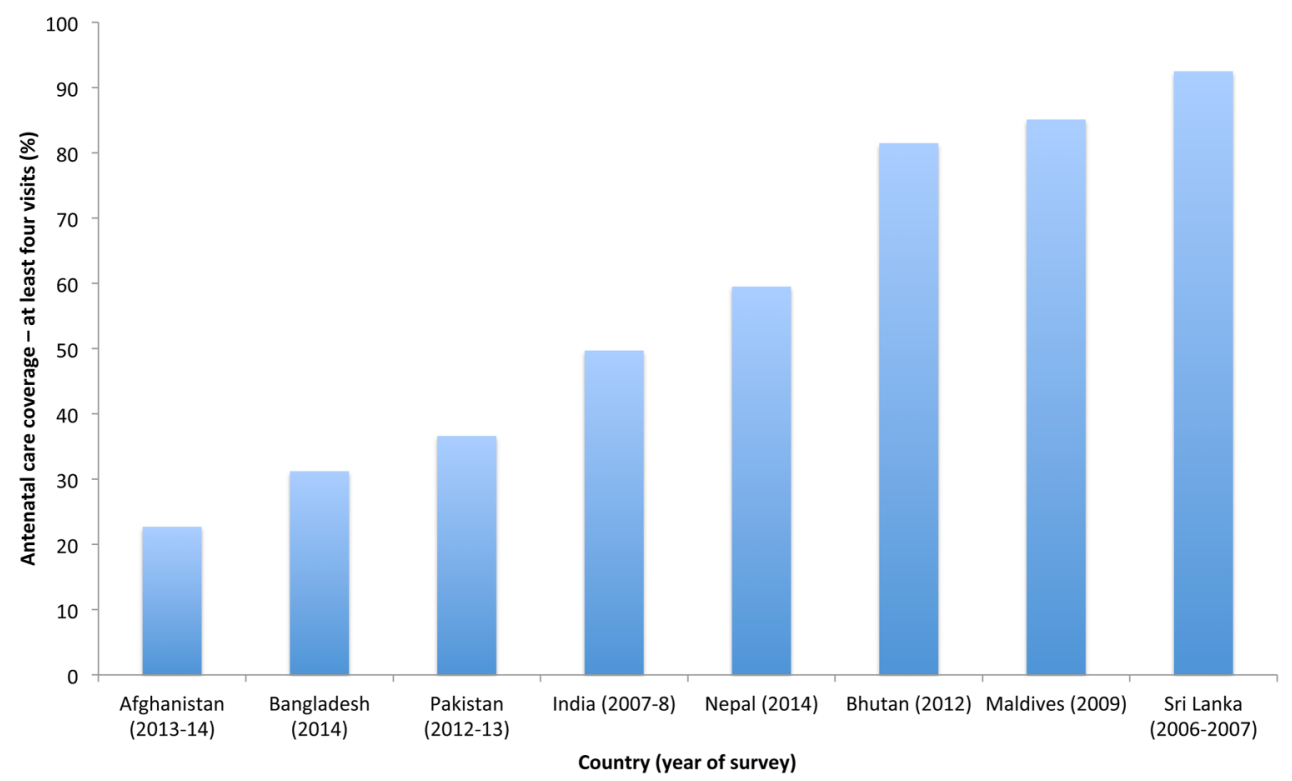

Figure 1 Percentage of women aged 15-49 years with a live birth who received antenatal care four or more times, 2007-2014. ${ }^{9}$

There are a number of barriers to achieving equitable coverage of essential MNCH services, including inequitable distribution of health services and personnel, cultural norms around health service usage and difficulties with access for non-citizens. ${ }^{26}$ The terrain and lack of infrastructure in some countries makes it challenging for governments to ensure that the whole population has access to health services. In Afghanistan, a lack of basic infrastructure such as roads and bridges, and security problems in some areas, mean that some communities do not have access to basic health services. ${ }^{27} 28$ The Basic Public Health System is in place in districts where $85 \%$ of the population lives, but only $57 \%$ of the population has access to a public health facility within 1 hour's walk. ${ }^{29}$ Slow uptake of innovative and pro-equity service delivery mechanisms, such as community health services, has prevented these geographic barriers from being more consistently and effectively addressed.

In Bhutan, physical accessibility to services is defined as the proportion of the population that is within 3 hours walking distance to a health service, ${ }^{30}$ with some unable to walk the distance or to afford transport. In the Maldives, the spread of the population across 187 different islands means that travel by boat or air to access health services is not only time consuming but expensive and often unreliable. ${ }^{31}$ This can, in particular, be a problem for those pregnant women who end up being referred to birthing facilities only when they are very close to the time of birth.

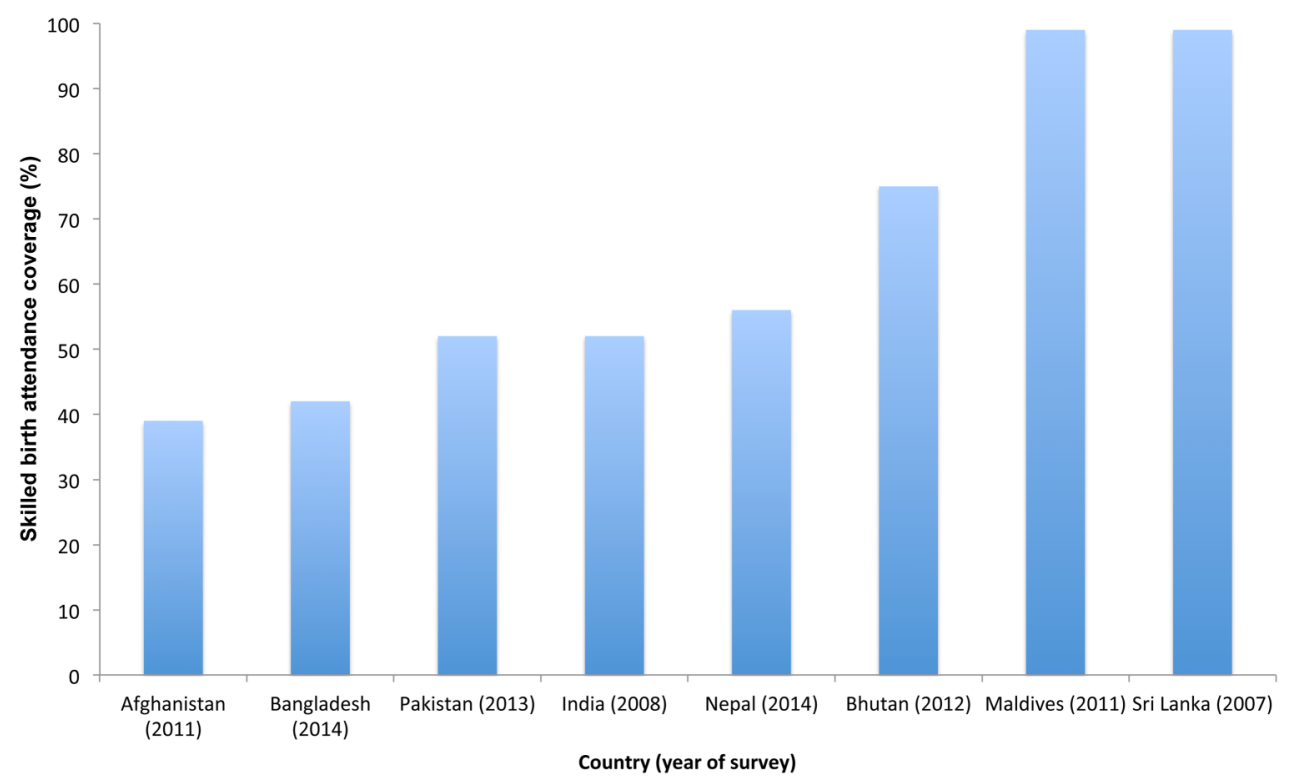

Figure 2 Percentage of births attended by skilled health staff, 2007-2014. ${ }^{10}$ 
Table 1 Coverage indicators*

\begin{tabular}{|c|c|c|c|c|c|c|}
\hline \multirow[b]{2}{*}{ Country } & \multicolumn{3}{|c|}{ Promotion and prevention coverage (\%) } & \multicolumn{3}{|c|}{ Treatment coverage (\%) } \\
\hline & $\begin{array}{l}\text { Pregnancy } \\
\text { care: } 4 \\
\text { antenatal } \\
\text { visits }^{9}\end{array}$ & $\begin{array}{l}\text { Child } \\
\text { undernutrition: } \\
\text { exclusive } \\
\text { breastfeeding in } \\
\text { under } \\
6 \text {-month-olds }{ }^{11}\end{array}$ & $\begin{array}{l}\text { Child } \\
\text { vaccination: } \\
\text { DTP3 }^{12}\end{array}$ & $\begin{array}{l}\text { Maternal care: } \\
\text { skilled birth } \\
\text { attendance }^{10}\end{array}$ & $\begin{array}{l}\text { Treatment of } \\
\text { child illness: } \\
\text { children aged } \\
<5 \text { years with } \\
\text { diarrhoea } \\
\text { treated with } \\
\text { ORT }^{13}\end{array}$ & $\begin{array}{l}\text { Treatment of } \\
\text { child illness: } \\
\text { children aged } \\
<5 \text { years with ARI } \\
\text { symptoms } \\
\text { receiving } \\
\text { antibiotics }^{13}\end{array}$ \\
\hline Bangladesh & 31.2 & 55 & 95 & 42 & 80.6 & 71.4 \\
\hline Bhutan & 81.5 & 49 & 99 & 75 & 80.5 & 48.7 \\
\hline India & 49.7 & 46 & 83 & 52 & 26.0 & 12.5 \\
\hline Maldives & 85.1 & 48 & 99 & 99 & 62.5 & Data not available \\
\hline
\end{tabular}

*Adapted from Boerma et al. ${ }^{8}$ Please note that country data refer to different years (dependent on latest data from source).

Data reflects the latest international estimates: for more detail see 'limitations' on $p$ 8-9.

\section{QUALITY OF CARE}

Despite availability of some services improving in recent years through a variety of schemes and plans, healthcare quality remains a problem in most countries. There has been too little investment in essential health services (including primary care) as well as inefficient spending. Wider system factors affect quality of care. Countries often lack sufficient numbers of appropriately trained staff, suffer from weak infrastructure and have inadequate supplies to provide universal coverage of essential services.

In Bangladesh, some people choose not to use public health facilities because of quality issues, including: a shortage of skilled health workers (particularly in rural areas), under-staffed and overcrowded facilities and a lack of equipment. ${ }^{32}$ In India, the government's health system is run through the states and is set up to offer free/low priced health services to all Indian citizens. ${ }^{33}$ However, these services often have a lack of medically trained staff, a shortage of medicine, high rates of absenteeism, limited opening hours, an unequal distribution of resources, limited national standards and poor accountability mechanisms. ${ }^{18} 33-36$

Even in countries that show stronger progress towards UHC, quality challenges remain. In Bhutan, inadequate human resources (including skilled birth attendants) is still a problem, as are insufficient equipment and commodities for emergency obstetric and newborn care. ${ }^{37} 38$

Poor governance of the health sector as a whole has been a criticism of many countries in the region and contributes to low quality healthcare. In Afghanistan, many service providers lack strong management skills to
Figure 3 Percentage of women aged $15-49$ years with a live birth who received antenatal care four or more times, by wealth quintile, 2005-2012. ${ }^{14}$

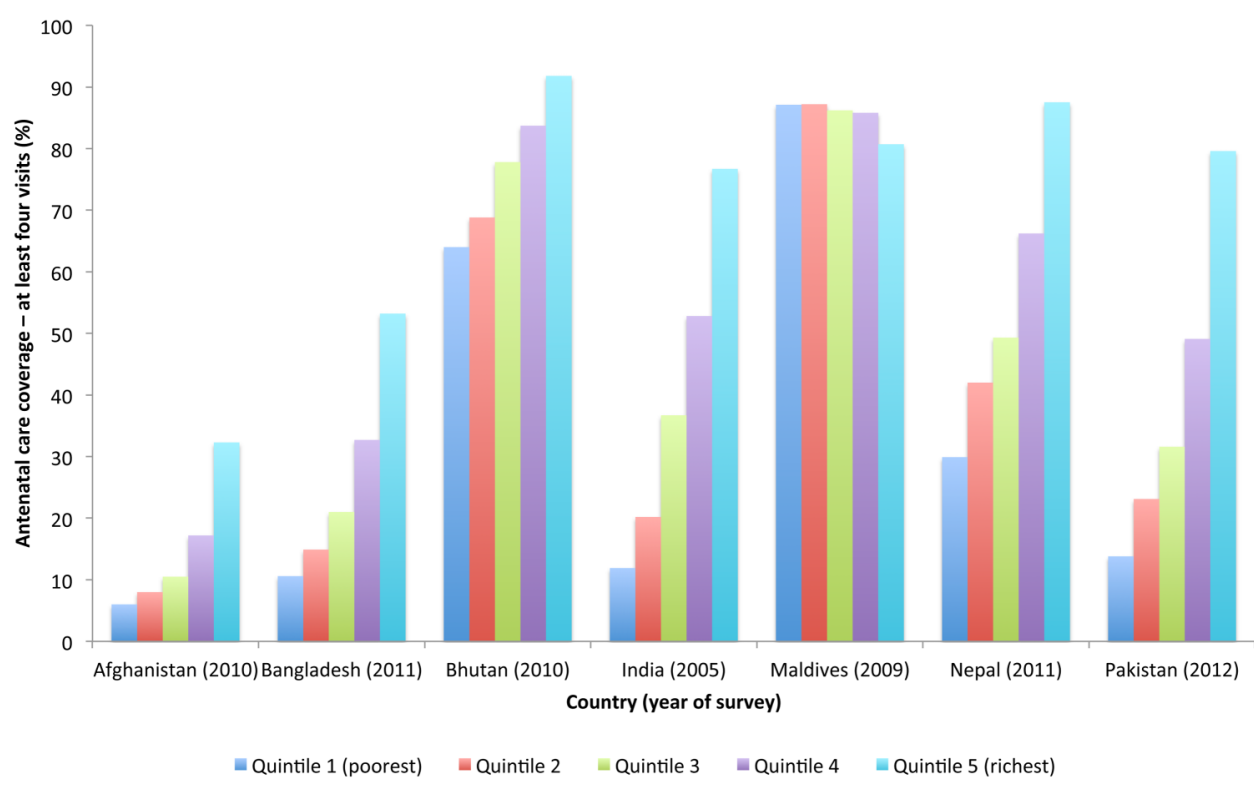




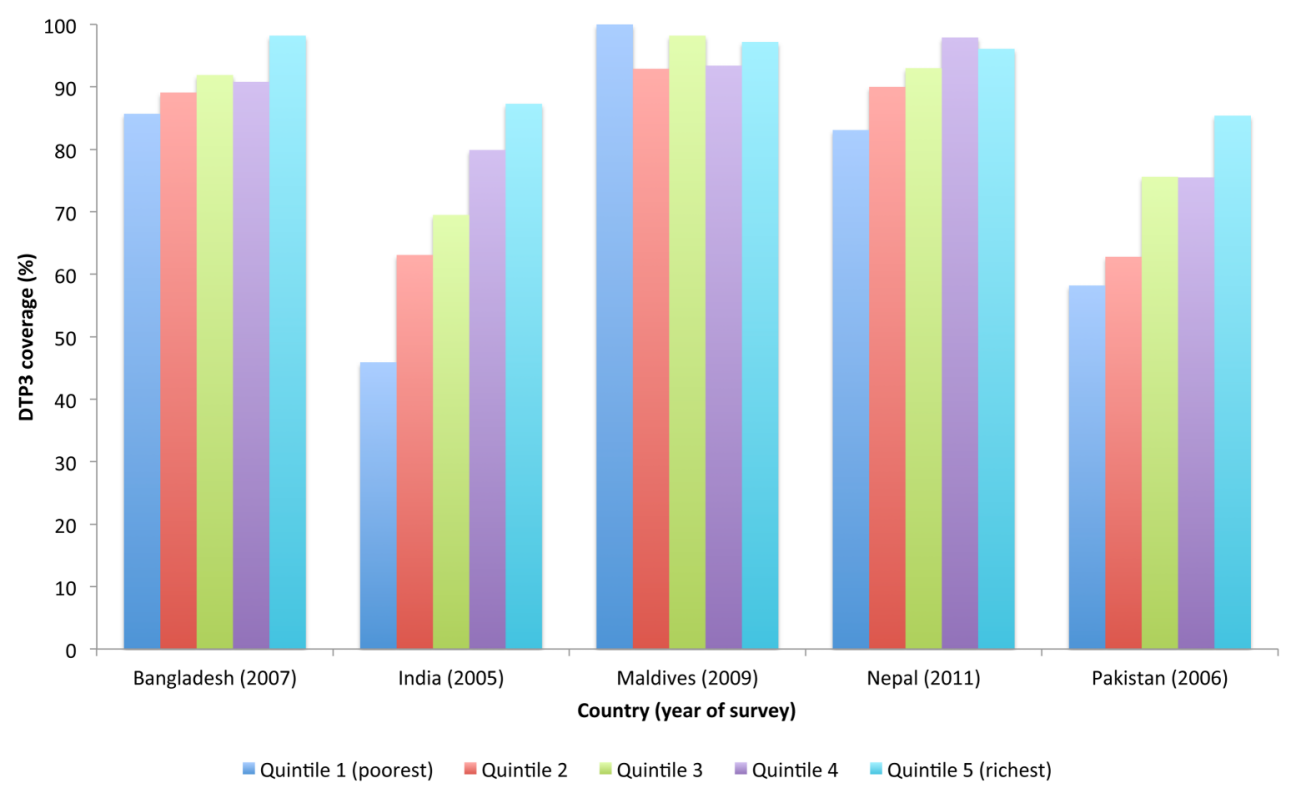

Figure 4 Percentage of surviving infants who received the third dose of DTP-containing vaccine, by urban wealth quintile $2005-2011 .{ }^{16}$

enable them to address quality issues and there is weak subnational governance. ${ }^{39}$ Although there is a comprehensive quality improvement national guideline, it has not yet been implemented fully.

Improved governance to ensure better coordination between different health services also needs to improve in many countries. In Pakistan, the health system with its various tiers and delivery mechanisms is fragmented. There is a range of service providers and funders, including local government, social security organisations, non-government organisations and private institutions. Resources are often wasted through duplication of work and a focus on tackling specific diseases rather than a whole systems approach. ${ }^{40}$ Weak governance with frail accountability mechanisms not only contributes to low quality healthcare but also coverage of services, and is not being consistently addressed.

Health management information systems also need strengthening to improve quality of care. A review by the WHO in the South East Asia region revealed several problems with health-related data, including: delays in receiving data, incomplete data, extraneous data in the system, data not suitable for decision-making and a lack of disaggregation. ${ }^{41}$

\section{FINANCIAL RISK PROTECTION}

Out-of-pocket expenditure (OOPE) provides an overview of a key dimension of UHC-financial risk protection. While this measure alone is insufficient to fully understand the level of financial insecurity faced by families, it gives an indication of the state of UHC in countries where data are available. Many countries in South Asia do not have systems or processes set up to measure impoverishing or catastrophic expenditures. Bangladesh has a results framework to monitor its national health sector programme, but this does not include data on coverage of financial risk protection. ${ }^{8}$ Attempts to assess catastrophic expenditures have been undertaken using surveys ${ }^{42}$ but recent data for all South Asian countries are not available.

Since the 2005 WHO resolution stating that all citizens should have access to health services without suffering financial hardship, ${ }^{1}$ OOPE as a proportion of total health expenditure ${ }^{\mathrm{i}}$ has fallen in some South Asian countries. However, OOPE remains generally high, accounting for between $18 \%$ and $67 \%$ of total health expenditure in 2014. Although these figures have reduced over time in some countries, overall progress to reduce OOPE is slow (figure 5).

OOPE prevents people from accessing healthcare. In Pakistan, the Core Welfare Indicators Questionnaire 2006-2007 found the main reason for not visiting health services when unwell was that treatment was too expensive $(52 \%) .{ }^{44}$ Similarly, in India, OOPE has historically prevented people from accessing care. In 2004, it was estimated that $28 \%$ of illnesses in rural areas and $20 \%$ in urban areas were not treated because of financial constraints. $^{45}$

In order to ensure citizens have access to health services, without suffering financial hardship, measures need to be in place to protect people from financial risk. As a first step, governments need to invest adequately in the health system, measured by the

${ }^{\mathrm{i}}$ The World Bank ${ }^{43}$ defines total health expenditure as the sum of public and private health expenditure. It covers the provision of health services (preventive and curative), family planning activities, nutrition activities and emergency aid designated for health, but does not include provision of water and sanitation. 


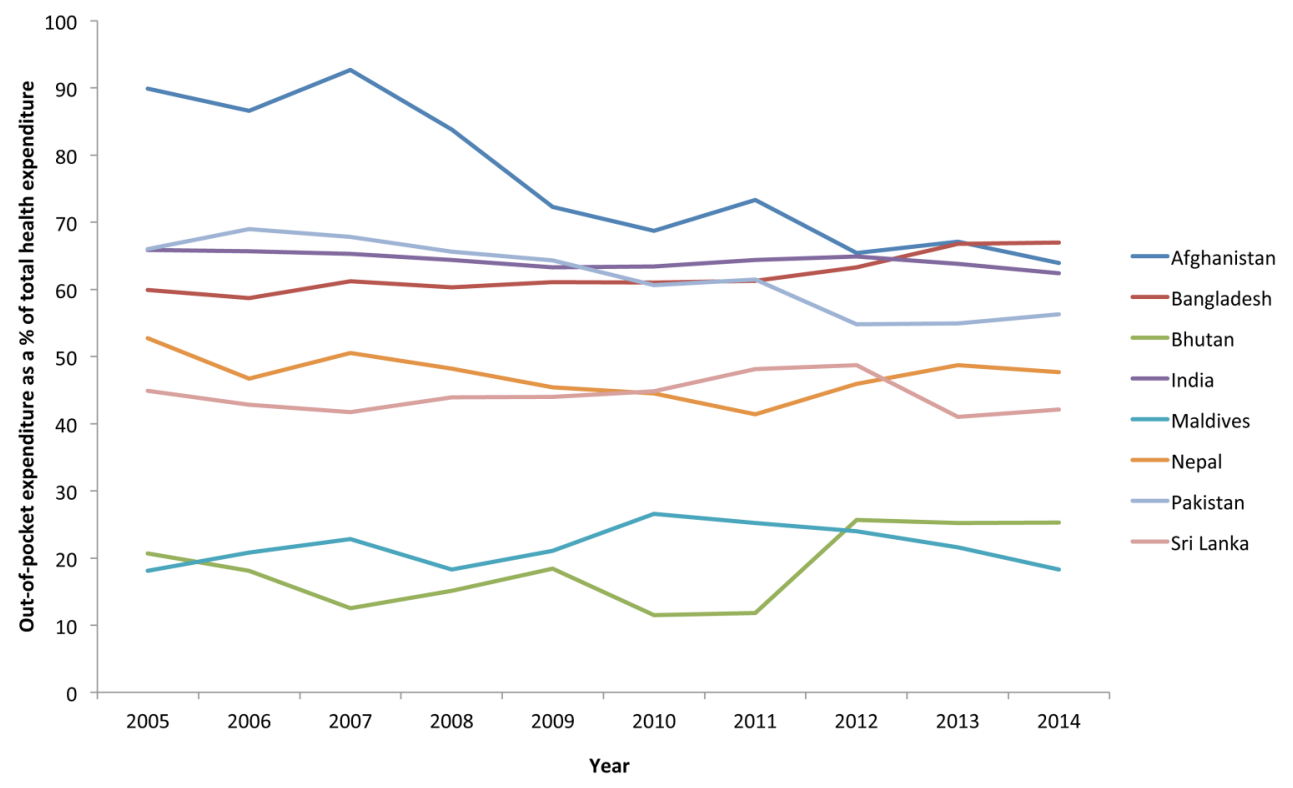

Figure 5 Out-of-pocket expenditure as $\%$ of total health expenditure (2005-2014). ${ }^{43}$

proportion of Gross Domestic Product (GDP) ${ }^{\mathrm{ii}}$ spent on public health expenditure. ${ }^{\text {iii }}$ In 2014, this varied considerably across South Asia, from $0.9 \%$ in Pakistan to $10.8 \%$ in the Maldives. Over time, the largest countries have seen only marginal increases in spending (figure 6). In contrast, European countries with established UHC spend considerably more on health overall (in 2014, the UK spent $7.6 \%$ of GDP on public health expenditure; Germany spent $8.7 \%$; and France spent 9.0\%). ${ }^{46}$ Although this does not include maternal and child health-specific breakdowns, it does give an insight into overall investment in health. Child health subaccounts would help with targeting funding allocations.

Once sufficient funding is allocated to health services, other issues need to be addressed to prevent people from catastrophic spending on health. Often when services are meant to be free, patients still end up paying. In Bangladesh, primary care and basic medicines are, in theory, covered by public spending, yet drugs often have to be bought from pharmacies. ${ }^{47}$ The reality is that the majority of people pay for services ${ }^{48}$ with fee exceptions for the poor not always implemented due to shortages in medicine supplies and unofficial payments. ${ }^{47}{ }^{49}$ Similarly, in Nepal, there are difficulties implementing fee waivers

\footnotetext{
ii The World Bank (2015e $)^{43}$ defines GDP as: "the value of all final goods and services produced in a country in one. GDP can be measured by adding up all of an economy's incomes-wages, interest, profits and rents-or expenditures-consumption, investment, government purchases, and net exports (exports minus imports). Both results should be the same because one person's expenditure is always another person's income, so the sum of all incomes must equal the sum of all expenditures".

iiiThe World Bank ${ }^{46}$ defines public health expenditure as capital spending from government (central and local) budgets, external borrowings and grants (including donations from international agencies and non-governmental organisations) and social (or compulsory) health insurance funds.
}

due to a lack of available drugs. ${ }^{47}$ In India, the majority $(72 \%)$ of OOPE was spent on medicines, ${ }^{34}$ with rising costs of drugs the main reason for increasing medical care costs. ${ }^{45}$ A patient being detained when their healthcare bills could not be paid, has also been reported. ${ }^{50}$

There also needs to be a focus on maximising the impact of expenditure. The National Institute for Health and Care Excellence (NICE) International, for example, is working with the Indian government on priority setting and health technology assessment (reviewing clinical and economic effectiveness of medicines and treatments) to help it achieve UHC. ${ }^{51}$

To strengthen financial protection, countries are taking a number of different approaches. The public health system in Sri Lanka is funded from general tax revenue, with a small proportion $(<5 \%)$ coming from international development assistance. The majority of spending comes from the central government (62\%) and provincial governments $(36 \%)$, with small contributions from local governments at the municipality level. ${ }^{52}$

In the Maldives, the population is covered by a universal health insurance scheme called Aasandha, which is funded by the government ${ }^{53}$ and provides the majority of care in the country. ${ }^{54}$ Aasandha has made considerable progress, with its pledge for achieving UHC recently commended by the WHO Regional Director for South East Asia. ${ }^{55}$

In India, there are a number of health insurance schemes available across the country, the largest of which is Rashtriya Swasthya Bima Yojana (RSBY), ${ }^{45}$ aiming to improve access to inpatient services for the poor by providing them with health insurance. ${ }^{33}$ Early studies suggest that the scheme has made a difference to financially protecting the poor for the covered procedures, but the scheme does not cover the common ambulatory care service $^{33}$ and concern has been raised over the cap on 
Figure 6 Public health expenditure as a percentage of gross domestic product, 2005$2013 .{ }^{46}$

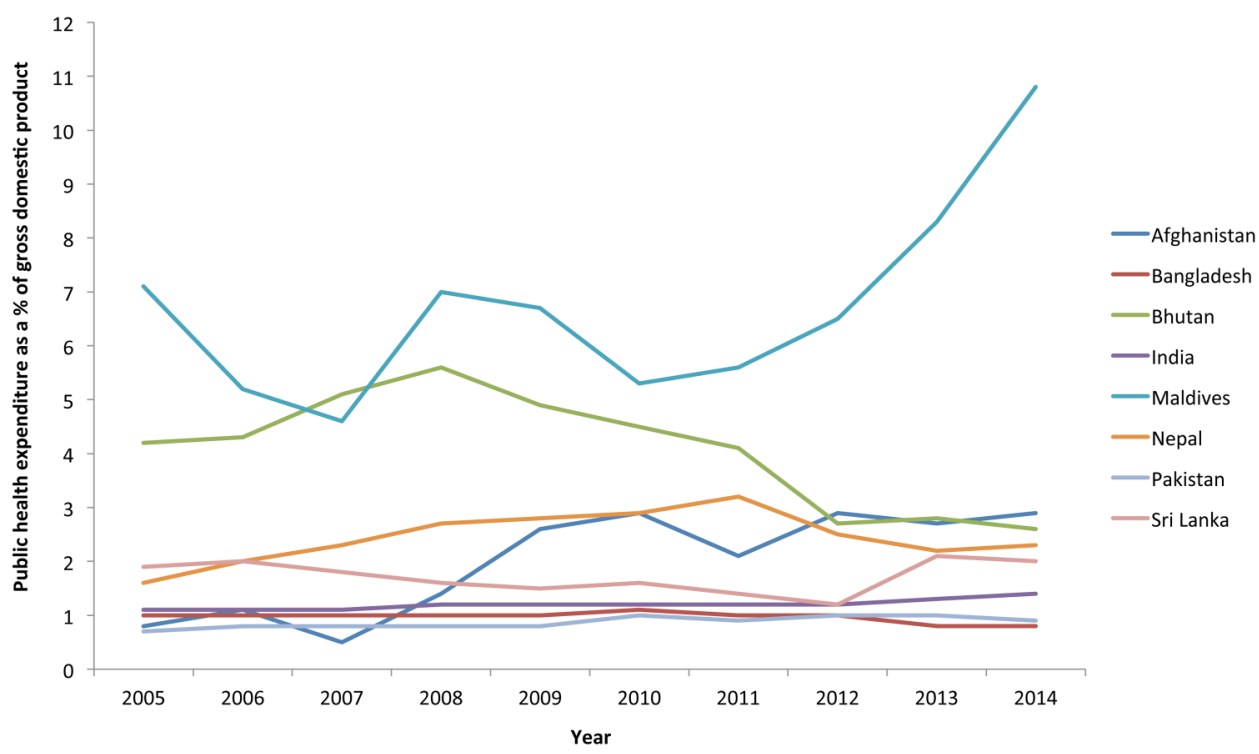

financial protection. ${ }^{56}$ In addition to this, researchers have found that in some areas people covered under RSBY are still making OOPE payments. ${ }^{57}$ There are also concerns about fraud; the quality of the services on offer; and a lack of coordination between RSBY and other schemes. ${ }^{33} 58$ These problems could partly be due to the lack of investment by the government: the increase in government health funding has been small, ${ }^{59}$ with the scheme contributing $<0.3 \%$ to total health expenditure in $2011 .{ }^{33}$ The High-Level Expert Group for UHC argues that the government can achieve UHC through providing universal health insurance. ${ }^{60}$ However, to achieve the government's plans of developing the largest health insurance scheme in the world, significant investment will be needed, with the High-Level Expert Group arguing that public funding will need to rise to at least $2.5 \%$ of GDP by 2017 , and $3 \%$ of GDP by 2022, if the proposed system is to be implemented. ${ }^{60}$ Given the government's current health funding, this increase seems unlikely.

In Bangladesh, the healthcare financing strategy for 2012-2032, developed by the Ministry of Health and Family Welfare (2012), proposes using a number of financing mechanisms to raise funds, including tax, prepayment schemes and donor funding. ${ }^{61}$ As part of the strategy, a social health protection scheme is proposed, paid for through payroll tax and subsidised by general revenue, with compulsory membership for people working in the formal sector and voluntary membership for the informal sector. ${ }^{61}$ However, whether such an ambition is achievable has been questioned, with concerns that a successful national health insurance scheme might not be possible in a country where a third of the people live below the poverty line and the majority are not in formal employment. ${ }^{21}$

\section{MOVING FORWARD}

Political aspirations for UHC are high in South Asia. Countries have made pledges for UHC in constitutions, national health plans and high-level ministerial speeches. Some countries have been discussing the concept of UHC for decades. The Bhore Committee, as early as 1946, advised that India should 'provide a full range of healthcare for everyone who wishes to use it'. ${ }^{62}$ The Government of Sri Lanka has also been committed to providing free universal healthcare for all citizens since the 1930s. ${ }^{63}$ Other countries have included the concept of UHC in national policy more recently. Afghanistan's National Health Policy (2015-2020) outlines the government's aspiration to achieving UHC. ${ }^{29}$ Bhutan outlines an aspiration to UHC in its constitution. ${ }^{37}$ The Maldives' Health Master Plan outlines the country's vision for health for 2006-2015, which includes an aspiration to provide social health insurance and create a needs-based, affordable and quality health service for all, ${ }^{54}$ and, in 2012, the government introduced Aasandha, a universal health insurance scheme. ${ }^{64}$ Nepal's new National Health Policy (2014/2015) aims to provide high-quality effective health services to everyone. ${ }^{65}{ }^{66}$ Bangladesh formally committed to achieving UHC in 2011, with the Prime Minister announcing it at the 64th World Health Assembly. ${ }^{48}$ In Pakistan, the Prime Minister committed to achieving UHC and announced a new nationallymanaged social health insurance scheme to provide 100 million people access to health services. ${ }^{67}$

Yet, although UHC is being discussed by governments in South Asia, this is not reflected in coverage figures, nor by financial allocations for health services.

Even where reported coverage of services is good, quality of care is often low. And, in terms of equity, those living in rural areas and of lower wealth status fare the worst. Although there are schemes and plans that attempt to address the poorest, there is not enough progress for the neediest populations.

To move forward in achieving UHC, governments and development partners need to prioritise interventions in three main areas: (1) removing financial and non- 
financial barriers to accessing and receiving high-quality healthcare; (2) increasing the amount of investment in essential health services, while ensuring effective and efficient spending, and (3) prioritising equity by allocating new resources to benefit the poorest first.

\section{Context specific solutions for countries}

While general principles for achieving UHC are well known, context specific solutions are needed, given the complexity of health systems in each country.

In Afghanistan, achieving UHC is particularly challenging due to the security issues the country faces. There is a need to decentralise more responsibility, apply mechanisms to regulate the private sector, examine public-private partnerships, improve financial risk protection, increase the number of female healthcare providers and expand health information systems. ${ }^{29}$

In Bangladesh, a five-point action plan has been proposed, which includes developing a national human resource policy and action plan to address the current workforce shortages; establishing a national insurance scheme; building an interoperable electronic health information system; strengthening the capacity of the Ministry of Health and Family Welfare; and creating a supra-ministerial council on health. ${ }^{21}$

In Nepal, coverage of good quality services needs to be addressed, and could be achieved through the planned health insurance scheme. Public sector spending necessary to rebuild following the 2015 earthquakes is a likely set-back to greater investments for achieving UHC in the short term.

Pakistan faces one of the steepest challenges, with a fragile security situation and recent devolution. Yet, what is clear is that action needs to be taken: to improve the quality of health services (including ensuring sufficient numbers of health workers in rural areas and the availability of medicines); to increase coverage of key $\mathrm{MNCH}$ services to address current inequities; and to prevent such a high proportion of people falling into poverty each month because of unaffordable medical costs - in 2005-2006, in any month, 4.7\% ended up in poverty due to medical expenses. ${ }^{44}$ Piloting social health insurance initiatives and testing their viability at the provincial level, with subsequent scale up based on lessons learnt, could be one approach that will capitalise on the devolution realities of Pakistan.

In India, the High Level Expert Group for UHC argues that the government can achieve UHC through providing universal health insurance that gives the whole population access to a good quality and affordable integrated national health system'. ${ }^{60}$ The current health insurance schemes could form a good foundation for the new system if existing problems could be tackled and coordination improved. ${ }^{33} 60$ To produce an adequate health system, the High-Level Expert Group argues that action needs to be taken in a number of areas, including: addressing health worker training and retention issues; restructuring governance; integrating the private sector; establishing a well-functioning health information and surveillance system; and introducing mechanisms to make drugs available at low cost for the whole population. ${ }^{60}$

\section{The role of civil society and development partners}

Where there has been recent dramatic progress towards UHC, such as in Thailand and a number of countries in Latin America, civil society has played a decisive role in reaching a tipping point for health reform and ensuring a focus on equity ${ }^{68-70}$ Many countries in South Asia also have vibrant civil society actors who have already played a key role in progress towards UHC, such as in Bangladesh. Civil society organisations can be key partners in building on existing achievements and also on addressing many of the challenges noted above. They can do this by developing solutions collaboratively, and also by critiquing initiatives where they fall short of their aims, and continuing to push for reforms and increased resources that fulfil the vision of UHC.

Development partners also have an important role in assisting governments to achieve UHC. These include transferring knowledge and building capacity and accountability of governments to: (1) formulate and assess the cost of plans and strategies, (2) identify critical service and system gaps through the use of evidencebased planning tools, (3) use latest and best evidence for improving quality of health services, (4) improve quality of data collection, both nationally and at district level, (5) reduce inequities by developing a disproportionate focus on the neediest and (6) understand fully the political economy for health in countries, and where financial flows lie, to free up more local and central resources for health. These actions are intrinsically linked to the identified problems with coverage, equity, quality of care and financial risk protection.

\section{CONCLUSION}

This analysis gives an overview of UHC in South Asia with regard to reported coverage of selected $\mathrm{MNCH}$ health indicators, equity, quality and financial risk protection. It outlines some of the key challenges for countries in the region. Limitations include focusing only on $\mathrm{MNCH}$. Further analysis is also required to understand how wider determinants of health impact on UHC for mothers and children. Another limitation is the reliability of comparable data between countries. In this analysis, we have mostly used data that have already been compared between countries by recognised agencies such as the World Bank, the WHO and UNICEF-and some of this data goes back a decade. We recognise that other individual data sources and surveys provide more recent and sometimes startlingly different estimates, which only reinforces the need for accurate measurement and accountability in health systems.

Seven of the eight countries in South Asia have national health policies that commit to providing health services for their population, with the exception of 
Pakistan, where responsibility for health lies largely with each province, following the government's recent devolution. There are strong examples of ongoing successes in countries such as Bhutan, the Maldives and Sri Lanka. Related to this success are factors such as lower OOPE and higher spending on health. Afghanistan, Bangladesh, India, Nepal and Pakistan are at different stages of planning how they can build on their existing health systems to achieve UHC. By focusing on coverage of interventions, quality of care, equity, financial risk protection and context-specific solutions, civil society and development partners can technically assist governments to reduce mortality and morbidity, increase health and well-being, and support sustainable and equitable development of health systems.

Handling editor Seye Abimbola

Twitter Follow Douglas Noble at @douglasnoblemd

Contributors KS conducted the literature review, interviewed key stakeholders, drafted the first version of the manuscript and contributed to later versions. DJN conceived the idea for the paper, was involved in the conception of the first draft and contributed to later versions. KR, TO, ASA, GB, TG, RJ, LK, HR, IVS and SV reviewed a longer internal report on which this paper is based, as well as contributing to the manuscript. MC reviewed and contributed to the manuscript. All the authors approved the final manuscript.

Disclaimer The opinions expressed in this paper are solely those of the authors and do not necessarily represent the views or policies of UNICEF.

Competing interests None declared

Provenance and peer review Not commissioned; externally peer reviewed.

Data sharing statement No additional data are available.

Open Access This is an Open Access article distributed in accordance with the Creative Commons Attribution Non Commercial (CC BY-NC 4.0) license, which permits others to distribute, remix, adapt, build upon this work noncommercially, and license their derivative works on different terms, provided the original work is properly cited and the use is non-commercial. See: http:// creativecommons.org/licenses/by-nc/4.0/

\section{REFERENCES}

1. World Health Organization. Resolution WHA58.33. Sustainable health financing, universal coverage and social health insurance 2005. Fifty Eighth World Health Assembly; Geneva, 16-25 May 2005 (WHA58/2005/REC/1). Available from World Health Organization. http://apps.who.int/gb/ebwha/pdf_files/WHA58-REC1/ english/A58_2005_REC1-en.pdf (accessed 15 Jun 2016)

2. United Nations. General Assembly, sixty-seventh session, Agenda item 123, Global health and foreign policy; 2012. Available from United Nations. http://www.un.org/ga/search/view_doc.asp? symbol=A/67/L.36\&referer=http://www.un.org/en/ga/info/draft/index. shtml\&Lang=E (accessed 15 Jun 2016)

3. Kim JY, Chan M. Poverty, health, and societies of the future. JAMA 2013;310:901-2

4. United Nations. Sustainable Development Goals; 2015 (accessed 15 October 2015). Available from the United Nations. https:// sustainabledevelopment.un.org/?menu=1300

5. World Health Organization. Health systems financing: the path to universal health coverage. Available from World Health Organisation 2010. http://www.who.int/whr/2010/10_summary_en.pdf?ua=1

6. United Nations. The Millenium Development Goals Report 2014. United Nations, 2014. Available from United Nations. http://www.un. org/millenniumgoals/2014\%20MDG\%20report/MDG\%202014\% 20English\%20web.pdf (accessed 15 Jun 2016)

7. World Health Organization and World Bank Group. Monitoring progress towards universal health coverage at country and global levels: framework, measures and targets. Geneva: WHO, 2014. http://apps.who.int/iris/bitstream/10665/112824/1/WHO_HIS_HIA_14. 1_eng.pdf (accessed 19 Feb 2016).
8. Boerma T, AbouZahr C, Evans D, et al. Monitoring intervention coverage in the context of universal health coverage. PLoS Med 2014;11:e1001728.

9. World Health Organization. Global Health Observatory Data Repository. Women, data by country [Data set]. 2015. http://apps. who.int/gho/data/node.main.REPWOMEN39?lang=en (accessed 4 Jun 2016).

10. The World Bank. Data: births attended by skilled health staff [Data set]. 2015a. http://data.worldbank.org/indicator/SH.STA.BRTC.ZS (accessed 4 Jun 2016).

11. The World Bank. Data: exclusive breastfeeding (\% of children under 6 months) [Data set]. 2016. http://data.worldbank.org/indicator/SH. STA.BFED.ZS (accessed 4 Jun 2016)

12. World Health Organization. WHO-UNICEF estimates of DTP3 coverage. 2015. http://apps.who.int/immunization_monitoring/ globalsummary/timeseries/tswucoveragedtp3.html (accessed 4 Jun 2016).

13. World Health Organization. Global Health Observatory Data Repository. Care of children, data by country [Data set]. 2016. http://apps.who.int/gho/data/node.main.38?lang=en (accessed 4 Jun 2016).

14. World Health Organization. Global Health Observatory Data Repository. Economic status, data by country [Data set]; 2015b. Retrieved 19 February 2016 from http://apps.who.int/gho/data/view. main.94030 (accessed 4 Jun 2016).

15. UNICEF. UNICEF data: monitoring the situation of children and women. http://data.unicef.org/maternal-health/delivery-care.html (accessed 4 Jun 2016)

16. World Health Organization. Global Health Observatory Data Repository, DTP3 immunization Data by urban wealth quintile [Data set]. http://apps.who.int/gho/data/view.main.100210?lang=en (accessed 4 Jun 2016)

17. Countdown to 2015. Fulfilling the Health Agenda for Women and Children The 2014 Report; 2014. Available from: Countdown to 2015. http://www.countdown2015mnch.org/documents/2014Report/ Pakistan_Country_Profile_2014.pdf (accessed 15 Jun 2016)

18. Balarajan Y, Selvaraj S, Subramanian SV. Health care and equity in India. Lancet 2011;377:505-15.

19. De Costa A, Al-Muniri A, Diwan VK, et al. Where are healthcare providers? Exploring relationships between context and human resources for health Madhya Pradesh province, India. Health Policy 2009;93:41-7. Cited in Balarajan Y, Selvaraj S, Subramanian SV. Health care and equity in India. Lancet 2011;377: 505-15.

20. Government of India. Central bureau of health intelligence. Health infrastructure, national health profile (NHP) of India. New Delhi: Central Bureau of Health Intelligence, Government of India, 2008. Cited in Balarajan Y, Selvaraj S, Subramanian SV. Health care and equity in India. Lancet 2011;377:505-15.

21. Adams AM, Ahmed T, El Arifeen S, et al. Innovation for universal health coverage in Bangladesh: a call to action. Lancet 2014;382:2104-11.

22. BRAC University. Bangladesh Health Watch. Health workforce in Bangladesh: who constitutes the health care system? The state of health in Bangladesh, 2007. Dhaka: BRAC University, 2008. Cited in Ahmed SM, Evans TG, Standing $\mathrm{H}$, et al. Harnessing pluralism for better health in Bangladesh. Lancet 2013;382:1746-55.

23. Government of the People's Republic of Bangladesh, Ministry of Health and Family Welfare. Health, population and nutrition sector development program, July 2011-June 2016. Dhaka: Ministry of Health and Family Welfare, 2012. Cited in Adams AM, Ahmed T, El Arifeen $\mathrm{S}$, et al. Innovation for universal health coverage in Bangladesh: a call to action. Lancet 2014;382: 2104-111.

24. UNICEF. The state of the world's children 2015: executive summary; 2015. Available from UNICEF. http://www.unicef.org/publications/files/ SOWC_2015_Summary_and_Tables.pdf (accessed 28 Jun 2015)

25. UNICEF. Understanding Urban Inequalities in Bangladesh: a prerequisite for achieving Vision 2021. Dhaka: UNICEF, 2010. http://www.unicef.org/bangladesh/Urban_paper_lowres.pdf (accessed 19 Feb 2016).

26. Rockefeller Foundation, Save the Children, UNICEF and WHO. Universal health coverage: a commitment to close the gap. 2013. http://www.savethechildren.org.uk/resources/online-library/universalhealth-coverage-commitment-close-gap (accessed 19 Feb 2016).

27. Islamic Republic of Afghanistan, Ministry of Public Health. A basic package of health services for Afghanistan 2010/1389. Afghanistan: Ministry of Public Health, 2010.

28. Trani JF, Bakhshi $P$, Noor AA, et al. Poverty, vulnerability, and provision of healthcare in Afghanistan. Soc Sci Med2010;70:1745-55

29. Islamic Republic of Afghanistan, Ministry of Public Health. National Health Policy 2015-2020. Ministry of Public Health, Afghanistan; 2015.

30. World Health Organization. Bhutan: Country cooperation strategy at a glance. 2014a. Available from World Health Organization. http:// 
www.who.int/countryfocus/cooperation_strategy/ccsbrief_btn_en. pdf?ua=1 (accessed 15 Jun 2016)

31. Republic of Maldives, Ministry of Health and Gender. Maldives Health Profile, 2014. 2014. Available from the Government of Maldives. http://www.health.gov.mv/publications/13_1395305886_ Maldives_Health_Profile_2014_final_final.pdf (accessed 15 Jun 2016)

32. Ahmed SM, Hossain MA, Rajachowdhury AM, The health workforce crisis in Bangladesh: shortage, inappropriate skill-mix and inequitable distribution. Hum Resour Health 2011;9:3. Cited in Ahmed SM, Evans TG, Standing $\mathrm{H}$, et al. Harnessing pluralism for better health in Bangladesh. Lancet 2013; 382:1746-55.

33. Nagpal S. UNICO studies series 13. Expanding health coverage for vulnerable groups in India. Washington DC: The World Bank, 2013. http://documents.worldbank.org/curated/en/2013/01/17207220/ expanding-health-coverage-vulnerable-groups-india

34. International Institute for Population Sciences (IIPS) and Macro International. National Family Health Survey (NFHS-3), 2005-2006. Vol 1. Mumbai: IIPS. Cited in Planning Commission of India. (2011). High level expert group report on universal health coverage for India (No. id: 4646). http://planningcommission.nic.in/reports/genrep/rep_ uhc0812.pdf (accessed 15 Jun 2016)

35. Joint Learning Network on Universal Health Coverage. How and why India must introduce universal healthcare coverage. 2014. Available from Joint Learning Network. http://jointlearningnetwork.org/news/ how-and-why-india-must-introduce-universal-healthcare-coverage

36. Rao M, Rao KD, Kumar AK, Human resources for health in India. Lancet 2011;377:587-98. Cited in Kumar AK, Chen LC, Choudhury M, et al. Financing health care for all: challenges and opportunities. Lancet 2011;377:668-79.

37. The Royal Government of Bhutan, Ministry of Health. National Health Policy, 2011. Available from the World Health Organization. http://apps.who.int/medicinedocs/documents/s19416en/s19416en. pdf (accessed 15 Jun 2016)

38. UNICEF. UNICEF Annual Report 2013. Bhutan, 2013. Available from UNICEF. http://www.unicef.org/about/annualreport/files/Bhutan_ COAR_2013.pdf (accessed 3 Nov 2014).

39. Sabri B, Siddiqi S, Ahmed AM, et al. Towards sustainable delivery of health services in Afghanistan: options for the future. Bull World Health Organ 2007;85:712-18.

40. World Health Organization. Pakistan: country coordination strategy at a glance. 2013a. Retrieved from World Health Organization. http:// www.who.int/countryfocus/cooperation_strategy/ccsbrief_pak_en.pdf (accessed 15 Jun 2016)

41. World Health Organization. 10 point regional strategy for strengthening health information systems. 2006. http://www.searo.who.int/entity/ health_situation_trends/documents/10-Point_Regional_Strategy_for_ HIS_SEA-HS-226.pdf (accessed 19 Feb 2016).

42. Xu K, Evans DB, Kawabata $\mathrm{K}$, et al. Household catastrophic health expenditure: a multicountry analysis. Lancet 2003;362:111-7. Xu K, Evans DB, Carrin G, et al. Protecting households from catastrophic health spending. Health Aff 2007;26:972-83.

43. The World Bank. Glossary. 2016. www.worldbank.org/depweb/english/ beyond/global/glossary.html (accessed 4 Jun 2016).

44. Chandrasiri J, Anuranga $\mathrm{C}$, Wickramasinghe R, et al. The impact of out of pocket expenditures on families and barriers to use of health services in Pakistan: evidence from the Pakistan social and living standards measurement surveys 2005-2007. RETA-6515 country brief. Manila: Asian Development Bank, 2012.

45. Kumar AK, Chen LC, Choudhury M, et al. Financing health care for all: challenges and opportunities. Lancet 2011;377:668-79.

46. The World Bank. Data: health expenditure, public (\% of GDP) [Data set]; 2015c http://data.worldbank.org/indicator/SH.XPD.PUBL.ZS (accessed 4 Jun 2016)

47. Van Doorslaer E, O'Donnell O, Rannan-Eliya RP, et al. Paying out-of-pocket for health care in Asia: catastrophic and poverty impact. EQUITAP project: working paper 2. 2005

48. Mushtaque A, Chowdhury R, Bhuiya A, et al. Universal health coverage: the next frontier. Bangladesh Health Watch Report: Moving towards universal health coverage. Bangladesh Health Watch, 2012. Available from BRAC. http://www.jointlearningnetwork. org/resources/bangladesh-health-watch-report-2011-movingtowards-universal-health-coverag (accessed 15 Jun 2016)

49. Maeda A, Araujo A, Cashin C, et al. Universal health coverage for inclusive and sustainable development: a synthesis of 11 country case studies. Directions in development. Washington DC: World Bank, 2014.

50. The Hindu. Hospital detains newborn as parents fail to pay bill. http://www.thehindu.com/news/national/other-states/ hospital-detains-newborn-as-parents-fail-to-pay-bill/article7653045 ece (accessed 19 Feb 2016)

51. National Institute for Health and Care Excellence. Upcoming NICE International technical assistance activities in India; 2014 (accessed 15 October 2015). https://www.nice.org.uk/about/what-we-do/niceinternational/nice-international-projects/nice-international-in-india (accessed 15 Jun 2016)

52. Rannan-Eliya RP, Sikurajapathy L. Sri Lanka: good practice in expanding health care coverage. Research Studies Series 3. Colombo: Institute for Health Policy, 2009.

53. Ministry of Health and Gender. Maldives Health Profile, 2014. 2014. http://www.health.gov.mv/publications/13_1395305886_Maldives_ Health_Profile_2014_final_final.pdf (accessed 25 Sep 2014).

54. World Health Organisation. Country cooperation strategy at a glance: Maldives. 2014. http://www.who.int/countryfocus/cooperation strategy/ccsbrief_mdv_en.pdf?ua=1 (accessed 24 Sep 2014).

55. World Health Organisation Regional Office for South East Asia WHO Regional Director applauds Maldives vision for universal health coverage, 5 March 2014. 2014. http://www.searo.who.int/ mediacentre/releases/2014/pr1567/en/ (accessed 25 Sep 2014).

56. Duran A, Kutzin J, Menabde N. Universal coverage challenges require health system approaches; the case of India. Health Policy 2014;114:269-77.

57. Devadasan N, Seshadri T, Trivedi M, et al. Promoting universal financial protection: evidence from the Rashtriya Swasthya Bima Yojana (RSBY) in Gujarat, India. Health Res Policy Syst 2013;11:29.

58. Lagomarsino G, Garabrant A, Adyas A, et al. Moving towards universal health coverage: health insurance reforms in nine developing countries in Africa and Asia. Lancet 2012;380:933-43.

59. Reddy KS, Patel V, Jha P, et al. Towards achievement of universal health care in India by 2020: a call to action. Lancet 2011;377:760-8.

60. Planning Commission of India. High level expert group report on universal health coverage for India (No. id: 4646). Delhi: Public Health Foundation of India, 2011. http://planningcommission.nic.in/ reports/genrep/rep_uhc0812.pdf (accessed 15 Jun 2016)

61. Ministry of Health and Family Welfare. Expanding social protection for health: towards universal coverage-health care financing strategy 2012-2032. Dhaka: Health Economics Unit, Ministry of Health and Family Welfare, 2012. Cited in Adams AM, Ahmed T, El Arifeen S, et al. Innovation for universal health coverage in Bangladesh: a call to action. Lancet 2014;382:2104-11.

62. Devadasan N, Ghosh S, Nandraj S, et al. Monitoring and evaluating progress towards universal health coverage in India. PLoS Med 2014;11:e1001697.

63. Rockefeller Foundation, Save the Children, UNICEF and WHO. Universal health coverage: a commitment to close the gap. London: Save the Children, 2013. Available from Save the Children. http:// www.savethechildren.org.uk/sites/default/files/docs/Universal_ health coverage summary.pdf (accessed 15 Jun 2016)

64. The World Bank. Maldives Health Policy Note 2. 2013a. Available from The World Bank. http://www-wds.worldbank.org/external/ default/WDSContentServer/WDSP/IB/2013/09/26/000333037 20130926111127/Rendered/PDF/812480BRIOP12100Box037933 B00PUBLIC0.pdf (accessed 15 Jun 2016)

65. Government of Nepal, Ministry of Health and Population. Nepal Health Sector Support Programme-2 Implementation Plan, 20102015. 2010. Available from Nepal Health Sector Support Programme. http://www.nhssp.org.np/health_policy/Consolidated\% 20NHSP-2\%20IP\%20092812\%20QA.pdf (accessed 14 Oct 2014)

66. Government of Nepal, Ministry of Health and Population. National Health Policy 2071, draft version 1, 8 August 2014 (unofficial translation). 2014

67. Dawn.com [Internet]. National Health Insurance Scheme to cover 100 million Pakistanis; 2014 (cited 21 February 2015). http://www. dawn.com/news/1110761

68. Fleury S. Brazil's health-care reform: social movements and civil society. Lancet 2011;377:1724-5.

69. Heredia N, Laurell AC, Feo O, et al. The right to health: what model for Latin America? Lancet 2015;385:e34-7.

70. Rasanathan K, Posayanonda T, Birmingham M, et al. Innovation and participation for healthy public policy: the first National Health Assembly in Thailand. Health Expect 2012;15:87-96. 